\title{
The internalization pathway, metabolic fate and biological effect of superparamagnetic iron oxide nanoparticles in the macrophage-like RAW264.7 cell
}

\author{
GU JingLi ${ }^{1}$, XU HaiFei ${ }^{1 *}$, HAN YeHua ${ }^{2}$, DAI Wei ${ }^{2}$, HAO Wei ${ }^{1}$, WANG ChunYu ${ }^{3}$, \\ GU Ning ${ }^{3}$, XU HaiYan ${ }^{4} \&$ CAO JiMin ${ }^{1 *}$ \\ ${ }^{1}$ Department of Physiology and Pathophysiology, Institute of Basic Medical Sciences, Chinese Academy of Medical Sciences, \\ School of Basic Medicine Peking Union Medical College, Beijing 100005, China; \\ ${ }^{2}$ Center of Electromicroscope, Institute of Basic Medical Sciences, Chinese Academy of Medical Sciences, \\ School of Basic Medicine Peking Union Medical College, Beijing 100005, China; \\ ${ }^{3}$ State Key Laboratory of Bioelectronics, Jiangsu Laboratory for Biomaterials and Devices, School of Biological Science and \\ Medical Engineering, Southeast University, Nanjing 211189, China; \\ ${ }^{4}$ Department of Biomedical Engineering, Institute of Basic Medical Sciences, Chinese Academy of Medical Sciences, \\ School of Basic Medicine Peking Union Medical College, Beijing 100005, China
}

Received January 20, 2011; accepted March 29, 2011

\begin{abstract}
The potential applications of superparamagnetic iron oxide nanoparticles (SPIONs) in several nanomedical fields have attracted intense interest based on the cell-nano interaction. However, the mechanisms underlying cell uptake, the intracellular trail, final fate and the biological effects of SPIONs have not yet been clearly elucidated. Here, we showed that multiple endocytic pathways were involved in the internalization process of SPIONs in the RAW264.7 macrophage. The internalized SPIONs were biocompatible and used three different metabolic pathways: The SPIONs were distributed to daughter cells during mitosis; they were degraded in the lysosome and free iron was released into the intracellular iron metabolic pool; and, the intact SPIONs were potentially exocytosed out of the cells. The internalized SPIONs did not induce cell damage but affected iron metabolism, inducing the upregulation of ferritin light chain at both the mRNA and protein levels and ferroportin 1 at the mRNA level. These results may contribute to the development of nanobiology and to the safe use of SPIONs in medicine when administered as a contrast medium or a drug delivery tool.
\end{abstract}

iron oxide nanoparticles, contrast medium, macrophage, endocytosis, iron metabolism

Citation: $\quad$ Gu J L, Xu H F, Han Y H, et al. The internalization pathway, metabolic fate and biological effect of superparamagnetic iron oxide nanoparticles in the macrophage-like RAW264.7 cell. Sci China Life Sci, 2011, 54: 793-805, doi: 10.1007/s11427-011-4215-5

Nanomaterials have helped biologists to deepen and widen their research in areas ranging from the development of improved methodologies to new potential applications. Superparamagnetic iron oxide nanoparticles (SPIONs) have been of especial interest in several nanomedical fields such as cell labeling [1], cell therapy [2], drug delivery [3], hyperthermia [4], tissue repair [5], diagnostic imaging [6] and

*Corresponding author (email: xuhaifei0113@163.com; caojimin@126.com) magnetofection [7]. Most of these applications take advantage of the fact that SPIONs can exhibit magnetic properties in the presence of a magnetic field. However, much less is known about the interaction between SPIONs and the biological systems, from the pathways of their transmembrane transportation to the cell response to intracellular SPIONs and their metabolites, involved in the intracellular journey of SPIONs.

Endocytosis, a highly regulated complex process by 
which mammalian cells internalize macromolecules, could be a possible transport mechanism for nanoparticles. Based on the types of cargo transported, two endocytic pathways have been identified, phagocytosis and pinocytosis. Cell uptake of fluids and particles with sizes $<0.5 \mu \mathrm{m}$ is through pinocytosis and this process has been further subcategorized into macropinocytosis, clathrin-dependent endocytosis, caveolin-dependent endocytosis, and clathrin- and caveolin-independent endocytosis [8]. Large particles $(>0.5 \mu \mathrm{m})$, such as non-self organisms or senescent cells, are cleaned primarily by phagocytosis, an actin-dependent endocytic mechanism, involving phagocytes such as macrophages, dendritic cells and neutrophils [9]. Because of the conflicting results, there is still no consensus about the transport mechanisms of nanoparticles into cells [10-14]. It is thought that the mechanisms of nanoparticle uptake may differ with the types of cells or with the nanomaterials used in the experiments.

As for the intracellular destiny of SPIONs, Arbab et al. $[15,16]$ investigated the metabolic fate and biological effects of poly-L-lysine and protamine sulfate modified ferumoxides (dextran-coated superparamagnetic iron oxide nanoparticles) on HeLa cells, human mesenchymal stem cells (hMSCs) and primary macrophage. They found that intracellular iron could not be detected after 5-8 passages in rapidly dividing Hela cells labeled with the poly-L-lysineferumoxides, but endosomal iron nanoparticles could still be detected after seven weeks in the slowly dividing hMSCs. These observations indicated that iron nanoparticles could enter the daughter cells during cell division and therefore the nanoparticle load in the new daughter cells decreased. They also observed the differential effects of protamine sulfate ferumoxides on the expressions of two signaling proteins (transferrin receptor and ferritin) involved in iron metabolism in different cell lines including hMSCs, HeLa cells and primary macrophages. Their findings suggest that the cell response to the iron oxide nanoparticles may differ among various cell types.

Although SPIONs with different physical and chemical properties may have different pharmacokinetics and cellular distribution after administration into the body, the majority of the SPIONs are sequestered by the macrophages in the reticuloendothelial system of the liver, spleen, lymph, etc. [17]. Macrophages are essential components of the body defense system and are implicated in many pathophysiological conditions such as the development of atherosclerosis [18,19] and tumors [20]. Macrophage targeting nanoparticles may have applications in the diagnosis and therapy of certain diseases. Therefore, a study of the interaction between SPIONs and macrophages may help improve our knowledge of imaging diagnosis and drug delivery using SPIONs as a tool.

Here, we chose a macrophage-like murine cell line RAW264.7 to investigate the internalization pathways, the metabolic fate and the biological effect of dimercaptosuccinic acid (DMSA) modified SPIONs. The study tracks the
SPION from its first interaction with the cell membrane till its involvement in intracellular metabolic pathways and investigates the influence of SPIONs on cell viability and the expression of iron metabolism-related proteins in RAW264.7 cells.

\section{Materials and methods}

\subsection{Preparation of biocompatible SPIONs}

Dimercaptosuccinic acid (DMSA) coated $\gamma-\mathrm{Fe}_{2} \mathrm{O}_{3}$ nanoparticles were prepared according to the described method [21,22]. In brief, a solution of ferric and ferrous ions in a 2:1 molar ratio was prepared under $\mathrm{N}_{2}$. This was followed by the slow addition, with vigorous stirring for $60 \mathrm{~min}$, of a solution of $12.5 \%(\mathrm{w} / \mathrm{w}) \mathrm{N}\left(\mathrm{CH}_{3}\right)_{4} \mathrm{OH}$ to bring the solution to $\mathrm{pH} 13$. Black $\mathrm{Fe}_{3} \mathrm{O}_{4}$ precipitates were obtained and, after magnetic separation, immediately washed once with distilled water. The final precipitates were dispersed in deionized water and the solution was carefully titrated to $\mathrm{pH}$ 3.0. The stable $\gamma-\mathrm{Fe}_{2} \mathrm{O}_{3}$ nanoparticles were synthesized by aeration bubbling oxidization at $95^{\circ} \mathrm{C}$, and were then coated with DMSA. The particle size and morphology of DMSA- $\gamma-\mathrm{Fe}_{2} \mathrm{O}_{3}$ nanoparticles were determined by transmission electron microscopy (TEM, JEOL, JEM-200EX, Japan). The magnetic property of the DMSA- $\gamma-\mathrm{Fe}_{2} \mathrm{O}_{3}$ nanoparticles was evaluated by a vibrating sample magnetometer (VSM, Lakeshore 7407).

\subsection{Cell culture}

The macrophage-like cell line RAW264.7 (established from a tumor induced by Abelson murine leukemia virus), was purchased from the Cell Center, Peking Union Medical College, China. Cells were grown in Dulbecco's modified Eagle's medium (DMEM) supplemented with $10 \%$ fetal bovine serum (FBS), $100 \mathrm{mg} \mathrm{mL}^{-1}$ streptomycin, $100 \mathrm{U} \mathrm{mL}^{-1}$ penicillin in a humidified atmosphere with $5 \% \mathrm{CO}_{2}$ at $37^{\circ} \mathrm{C}$.

\subsection{Prussian blue staining}

RAW264.7 cells were seeded in 24-well plates at $8 \times 10^{4}$ cells/well for at least $24 \mathrm{~h}$ until they reached $80 \%$ confluency. They were then incubated with $25 \mu \mathrm{g}(\mathrm{Fe}) \mathrm{mL}^{-1}$ of SPIONs at $37^{\circ} \mathrm{C}$ for $10 \mathrm{~min}, 30 \mathrm{~min}, 1 \mathrm{~h}, 2 \mathrm{~h}, 3 \mathrm{~h}, 6 \mathrm{~h}, 12 \mathrm{~h}$ or $24 \mathrm{~h}$. Alternatively, the RAW264.7 cells were incubated with $25 \mu \mathrm{g}(\mathrm{Fe}) \mathrm{mL}^{-1}$ of SPIONs at $37^{\circ} \mathrm{C}$ for $6 \mathrm{~h}$, then the SPION-loaded RAW264.7 cells were cultured in fresh culture medium for another $1,3,6,12,24,36$, or $48 \mathrm{~h}$. At the various time intervals, the medium was aspirated, and the cell layer was washed once with phosphate buffered solution (PBS), followed by treatment in $4 \%$ buffered paraformaldehyde for $15 \mathrm{~min}$ at room temperature and then 
subjected to a final wash. The cell layer was exposed to a freshly prepared solution (1:1 volume) of $1 \mathrm{~N} \mathrm{HCl}$ and $10 \%$ $\mathrm{K}_{4}\left[\mathrm{Fe}(\mathrm{CN})_{6}\right]$ in distilled water for $10-15 \mathrm{~min}$ at room temperature. Cells were counterstained with nuclear fast red. Photographs were taken using a Nikon digital camera (DXM 1200; Nikon Corporation, Tokyo, Japan). The nucleus was stained red and the iron nanoparticle-containing cytoplasm was stained blue by this method. The concentration of SPIONs used in this study was equivalent to the iron composition in the nanoparticles.

\subsection{Preparation of cell samples for transmission elec- tron microscopy}

RAW264.7 cells were seeded in $25 \mathrm{~mL}$ flasks for at least $24 \mathrm{~h}$ until they grew to $80 \%$ confluency and were then incubated with $25 \mu \mathrm{g}(\mathrm{Fe}) \mathrm{mL}^{-1} \mathrm{SPIONs}$ at $37^{\circ} \mathrm{C}$ for $5 \mathrm{~min}, 10 \mathrm{~min}, 30$ min, $1 \mathrm{~h}, 3 \mathrm{~h}$ or $24 \mathrm{~h}$. Or, RAW264.7 cells were incubated with $25 \mu \mathrm{g}(\mathrm{Fe}) \mathrm{mL}^{-1}$ SPIONs at $37^{\circ} \mathrm{C}$ for $6 \mathrm{~h}$, then the SPION-loaded RAW264.7 cells were cultured in fresh culture medium for another 1, 3, 6, 12, 24, 36, or $48 \mathrm{~h}$. At the indicated times, cells were harvested by centrifugation at $1000 \mathrm{r} \mathrm{min}^{-1}$ for $4 \mathrm{~min}$. The pellets were fixed with $2.5 \%$ glutaraldehyde in $0.1 \mathrm{~mol} \mathrm{~L}^{-1}$ phosphate buffer $(\mathrm{pH} 7.2)$, then stored at $4^{\circ} \mathrm{C}$ before transmission electron microscopy (TEM) was performed. For the low temperature treatment, RAW264.7 cells were cultured at $4^{\circ} \mathrm{C}$ for $10 \mathrm{~min}$, the sequential procedures were the same as the above.

To study the possible internalization pathways of SPION in RAW264.7 cells, some selective endocytic inhibitors were used. In brief, RAW264.7 cells were pretreated with $10 \mathrm{mmol} \mathrm{L}^{-1}$ sodium azide and $50 \mathrm{mmol} \mathrm{L}^{-1}$ 2-deoxy-Dglucose, $10 \mu \mathrm{g} \mathrm{mL}^{-1}$ chlorpromazine, $5 \mu \mathrm{g} \mathrm{mL}^{-1}$ filipin III, $10 \mathrm{mmol} \mathrm{L}^{-1}$ methyl- $\beta$-cyclodextrin $(\mathrm{M} \beta \mathrm{CD}), 2.5 \mathrm{mmol} \mathrm{L}{ }^{-1}$ amiloride, $100 \mu \mathrm{g} \mathrm{mL} \mathrm{m}^{-1}$ oxidative low density lipoprotein (ox-LDL) or $10 \mu \mathrm{mol} \mathrm{L}{ }^{-1}$ cytochalasin D (all from Sigma) at $37^{\circ} \mathrm{C}$ for $30 \mathrm{~min}$, then co-incubated with $25 \mu \mathrm{g}(\mathrm{Fe}) \mathrm{mL}^{-1}$ of SPION in complete culture medium for another $1 \mathrm{~h}$.

\subsection{Transmission electron microscopy}

After repeatedly washing the cell samples, prepared as described above, with phosphate buffer, a secondary fixation was performed in $1 \%$ phosphate buffered osmium tetroxide in the dark for $1 \mathrm{~h}$ followed by repeated washing with phosphate buffer. The samples were then dehydrated by a graded ethanol series and acetone, infiltrated by a solution of epoxy resin and acetone $(2: 1, \mathrm{v} / \mathrm{v})$ overnight and then by only epoxy resin for $3 \mathrm{~h}$, and finally were embedded in epoxy resin and polymerized at $60^{\circ} \mathrm{C}$ for $48 \mathrm{~h}$. Semithin sections $(500 \mathrm{~nm})$ were cut by a RMC MT-X ultramicrotome, then toluidine blue staining was carried out to determine the area of interest for further trimming of embed blocks. Thus, precise ultra-thin sections could be cut. The sections were mounted on copper grids, stained with uranyl acetate and lead citrate in the dark at room temperature, and then washed thoroughly with distilled water. Images were collected using a transmission electron microscope (TEM, JEOL-1011, Japan) at $80 \mathrm{kV}$ with a GATAN digital camera (Gatan, USA).

\subsection{TEM-EDS analysis}

The prepared TEM samples were also analyzed with a transmission electron microscope (TEM, JEOL-2010F, Japan) equipped with an energy dispersive spectrometer (EDS) (INCA IET200 Oxford, USA) probe that, by qualitative analysis, can determine the local composition of target areas at the nanoscale level. The TEM images were taken at an acceleration voltage of $200 \mathrm{kV}$ with point resolution of $0.23 \mathrm{~nm}$. Energy dispersive spectra analysis was carried out to identify the element composition of selected areas.

\subsection{Spectrophotometric analysis}

To evaluate the intracellular iron content, the SPION-loaded RAW264.7 cell layer was dissolved for $1 \mathrm{~h}$ in $6 \mathrm{~N} \mathrm{HCl} \mathrm{(125}$ $\mu \mathrm{L} /$ well of a 48 -well plate), then $125 \mu \mathrm{L}$ of a solution of $5 \%$ $\mathrm{K}_{4}\left[\mathrm{Fe}(\mathrm{CN})_{6}\right]$ (Sinopharm Chemical Reagent Co., Ltd., Beijing, China) was added to each well, and finally the absorbance was read after $10 \mathrm{~min}$ at $690 \mathrm{~nm}$ in a multifunctional microplate reader (Synergy ${ }^{\mathrm{TM}} 4$, BioTek). The iron content was calculated using a standard curve prepared using an aqueous $\mathrm{FeCl}_{3} \cdot 6 \mathrm{H}_{2} \mathrm{O}$ (Sinopharm Chemical Reagent Co., Ltd., Beijing, China) solution (in concentrations ranging from 0 to $28 \mu \mathrm{g}(\mathrm{Fe}) \mathrm{mL}^{-1}$ ) under the same conditions. Each experiment was repeated in triplicate and the experiment was repeated three times.

\subsection{Inductively coupled plasma mass spectrometry}

To investigate if RAW264.7 cells could degrade SPION and release free iron into the extracellular environment, inductively coupled plasma mass spectrometry (ICP-MS) was performed. In brief, RAW264.7 cells were incubated with $25 \mu \mathrm{g}(\mathrm{Fe}) \mathrm{mL}^{-1}$ SPIONs at $37^{\circ} \mathrm{C}$ for $6 \mathrm{~h}$. After incubation, the SPION-loaded RAW264.7 cells were continuously cultured in fresh culture medium for another 1, 6, 24, 36, 48 or $72 \mathrm{~h}$. The supernatants were then collected at each of the different time points. The iron content in the supernatant was evaluated by ICP-MS.

\subsection{MTT assay}

The viability of SPION-loaded RAW264.7 cells was evaluated by MTT (3-(4,5-dimethylthiazolyl-2)-2,5-diphenyltetrazolium bromide) assay. RAW264.7 cells were pre-incubated with SPIONs at different concentrations for various times in a 96-well plate. After incubation, RAW264.7 cells 
were cultured for another $4 \mathrm{~h}$ in $0.5 \mathrm{mg} \mathrm{mL} \mathrm{m}^{-1}$ MTT-containing culture medium. Then the medium was carefully removed, $100 \mu \mathrm{L} /$ well dimethyl sulfoxide was added and the absorbance was measured at a detection wavelength of $570 \mathrm{~nm}$ and at a reference wavelength of $630 \mathrm{~nm}$ using a microplate reader (Synergy ${ }^{\mathrm{TM}} 4$, BioTek). The cell viability was expressed as a percentage based on a SPION-unlabeled control, which was by definition $100 \%$.

\subsection{Flow cytometry}

To analyze the intracellular generation of reactive oxygen species (ROS), the oxidation-sensitive probe 2',7'-dichlorofluorescein diacetate $\left(\mathrm{H}_{2} \mathrm{DCF}-\mathrm{DA}\right.$, Molecular Probes, Eugene, Oregon, USA) was used. Raw264.7 cells were seeded in 12-well plates at $6 \times 10^{4}$ cells/well for at least $24 \mathrm{~h}$ until they reached $80 \%$ confluency and they were then treated with $25 \mu \mathrm{g}(\mathrm{Fe}) \mathrm{mL}^{-1}$ SPIONs for the indicated times. After incubation with SPIONs, RAW264.7 cells were collected and loaded with $\mathrm{H}_{2}$ DCF-DA at a concentration of $10 \mu \mathrm{mol} \mathrm{L}{ }^{-1}$ at $37^{\circ} \mathrm{C}$ for $1 \mathrm{~h}$. After washing twice, flow cytometry was performed using a flow cytometer (Elitee ESP, Counlter, USA) with an excitation wavelength of $488 \mathrm{~nm}$ and an emission wavelength of $525 \mathrm{~nm}$. The ROS production was estimated by the fluorescence intensity at different time points, a rightward shift of the fluorescence tracing curve indicates an increase in ROS production while a leftward shift indicates an decrease in ROS production.

To measure the mitochondrial membrane potential $\left(\Delta \Psi_{\mathrm{m}}\right)$, rhodamine 123 (Rh123) was used as a fluorescent probe. Briefly, RAW264.7 cells were seeded in 12-well plates at $6 \times 10^{4} /$ well for at least $24 \mathrm{~h}$ until they reached $80 \%$ confluency, then treated with $25 \mu \mathrm{g}(\mathrm{Fe}) \mathrm{mL}^{-1}$ SPIONs for the indicated times. RAW264.7 cells were collected and loaded with Rh123 at a concentration of $50 \mu \mathrm{mol} \mathrm{L}{ }^{-1}$ at $37^{\circ} \mathrm{C}$ for 30 min. After washing three times with PBS, flow cytometry was performed using a flow cytometer (Elitee ESP, Counlter, USA) with an excitation wavelength of $488 \mathrm{~nm}$ and an emission wavelength of $525 \mathrm{~nm}$. The $\Delta \Psi_{\mathrm{m}}$ was assessed from the fluorescence intensity at different time points, a leftward shift of the fluorescence tracing curve indicates depolarization.

\subsection{Western blot}

To evaluate the effect of SPIONs on iron metabolism, Western blotting was used to examine the protein levels of iron regulatory protein 2 (IRP2), ferroportin 1 and ferritin-L in RAW264.7 cells pre-incubated with a fixed SPION concentration $\left(25 \mu \mathrm{g}(\mathrm{Fe}) \mathrm{mL}^{-1}\right)$ for different times $(0-24 \mathrm{~h})$ or in cells pre-incubated with different SPION concentrations $(0-100 \mu \mathrm{g}(\mathrm{Fe}))$ for a fixed time $(6 \mathrm{~h})$. SPION-(un)labeled RAW264.7 cells were lysed by $1 \times$ loading buffer $\left(50 \mathrm{mmol} \mathrm{L}^{-1}\right.$ Tris, $2 \%$ SDS, $10 \%$ glycerol, $100 \mathrm{mmol} \mathrm{L}^{-1}$ DTT, $0.1 \%$ bromophenol blue). Lysates were subjected to reducing SDS-PAGE on $10 \%$ gels for analysis of IRP2 or on $12 \%$ gels for analysis of ferritin light chain. The proteins were transferred to nitrocellulose membrane and the following antibodies and dilutions were used: rabbit polyclonal anti-IRP2 $1: 500$, goat polyclonal anti-FTL 1:500 (Novus Biologicals, CO, USA), mouse monoclonal anti- $\beta$-actin antibody $1: 1000$ (Santa Cruz Biotech., CA, USA). Secondary goat anti-rabbit, rabbit anti-goat, rabbit anti-mouse antibodies conjugated to horse radish peroxidase were used at 1:1000 dilutions (ICL, Inc., OR, USA). Bands were visualized by chemiluminescence (ECL plus Western Blotting Reagent, Santa Cruz Biotech., CA, USA).

\subsection{Real-time RT-PCR}

Total RNA isolation from SPION-labeled and unlabeled RAW264.7 cells was performed using TRIzol Reagent (Invitrogen, CA, USA) according to the manufacturer's protocol. RNA concentrations were determined by spectrophotometer readings at $260 \mathrm{~nm}$ and equal amounts of each RNA sample were used for the reverse transcription reaction. RT-qPCR was performed using the TransScript II Two Step qRT-PCR Supermix Kit (TransGen Biotech., Beijing, China) according to the manufacturer's protocol. The forward and reverse primers for the various target genes were designed as follows: $\beta$-actin: 5'-TCAAGATCATTGCTCCTCCTGAG-3', 5'-CTGCTTGCTGATCCACATCTG-3'; IRP2: 5'-GTGATTGTGACCGTGCCAATT-3'， 5'-ACCTAAAGGCTCTGTCTGGAAGTC-3'; ferritin-L: 5'-TTCCAGGATGTGCAGAAGCC-3', 5'-AAGAGGGCCTGATTCAGGTTC-3'; ferroportin 1: 5'-TCATTGCTCTAGAATCGGTCTT-3', 5'-CACACCATTGATAATGCCTCTTTC-3'. The cycle threshold values, corresponding to the PCR cycle number at which fluorescence emission reached a threshold above the baseline emission, were determined and the mRNA expression was calculated relative to the $\beta$-actin gene using the $2^{-\Delta \Delta C_{t}}$ method.

\subsection{Statistical analysis}

Data are presented as mean \pm standard deviation (SD). Statistical analysis was only performed when the experiments were carried out at least in triplicate. Analysis of variance followed by Newman-Keuls multiple comparisons was used. $P<0.05$ was considered to be significant.

\section{Results}

\subsection{Characteristics of the SPIONs}

DMSA coated $\gamma-\mathrm{Fe}_{2} \mathrm{O}_{3}$ nanoparticles were successfully prepared with satisfying stability and biocompatibility. The 
morphology and size distribution of the SPIONs were observed by TEM. As shown in Figure 1A, most of the SPIONs were quasi-spherical with an average diameter of 10 $\mathrm{nm}$. The magnetic property of the SPION was measured by VSM. The results (Figure 1B) indicated that the saturation magnetization was around $50 \mathrm{emu} \mathrm{g}^{-1}$. The synthesized SPIONs also showed superparamagnetic behavior, as evidenced by zero coercivity and remanence on the magnetization loops.

\subsection{SPION uptake by RAW264.7 cells}

To discover if SPIONs could be internalized by RAW264.7 cells, Prussian blue staining and TEM-EDS analyses were performed. As shown in Figure 2A, after incubation of the RAW264.7 cells with SPIONs for $24 \mathrm{~h}$, some particles, suspected to be nanoparticles, were found in the vesicles of the cells. The corresponding EDS spectra of the selected areas (Figure 2B) showed that the membrane-bound particles with high electron density were iron in nature. Iron was not detected in a randomly selected zone with no vesicles (Figure 2C). These data therefore confirmed the internalization of SPIONs.

The Prussian blue staining and spectrophotometric assays showed that SPION internalization was time- and concentration-dependent. More blue pigment could be found inside the cells with either the extended incubation times (Figure $3 \mathrm{~A}$ ) or with the higher SPION concentration (Figure 3C). RAW264.7 cells labeled with $25 \mu \mathrm{g}(\mathrm{Fe}) \mathrm{mL}^{-1}$ SPIONs for $24 \mathrm{~h}$ contained $(37.9 \pm 9.2) \mathrm{pg}$ iron/cell and $(40.3 \pm 6.1) \mathrm{pg}$ iron/cell for cells labeled for $48 \mathrm{~h}$. Cells incubated with culture medium contained only $(5.8 \pm 1.2) \mathrm{pg}$ iron/cell. However, the iron content of $(35.2 \pm 7.8) \mathrm{pg}$ iron/cell at $12 \mathrm{~h}$ was not significantly different from the iron content at the longer incubation times (Figure 3B). Figure 3D demonstrated that SPION uptake by RAW264.7 cells increased with higher
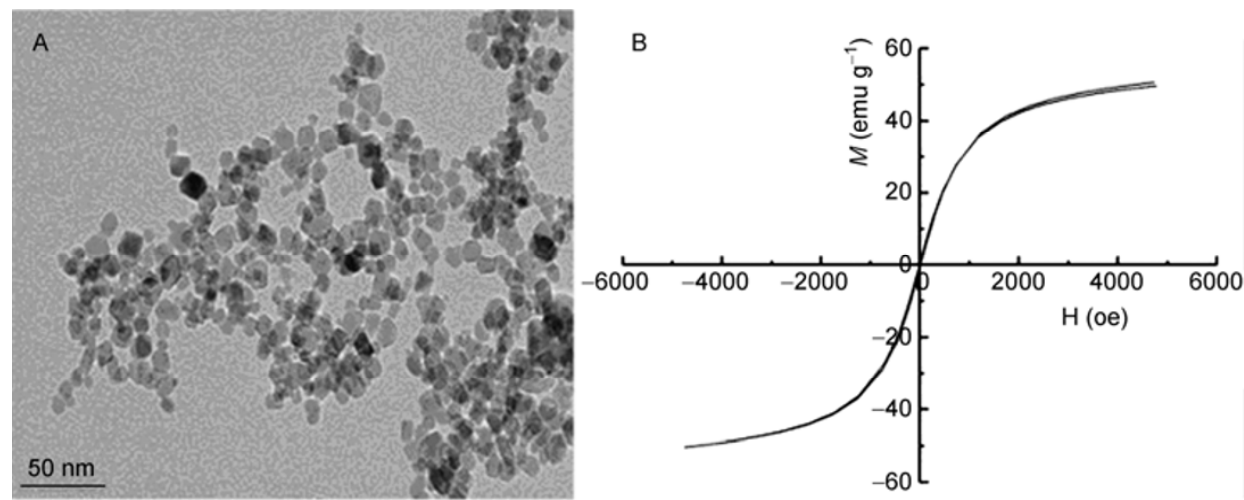

Figure 1 Characteristics of the SPIONs. A, A TEM image of SPIONs showing that most of the nanoparticles were quasi-spherical with an average diameter of $10 \mathrm{~nm}$. B, The magnetic property of the SPION; the saturation magnetization was about $50 \mathrm{emu} \mathrm{g}^{-1}$.

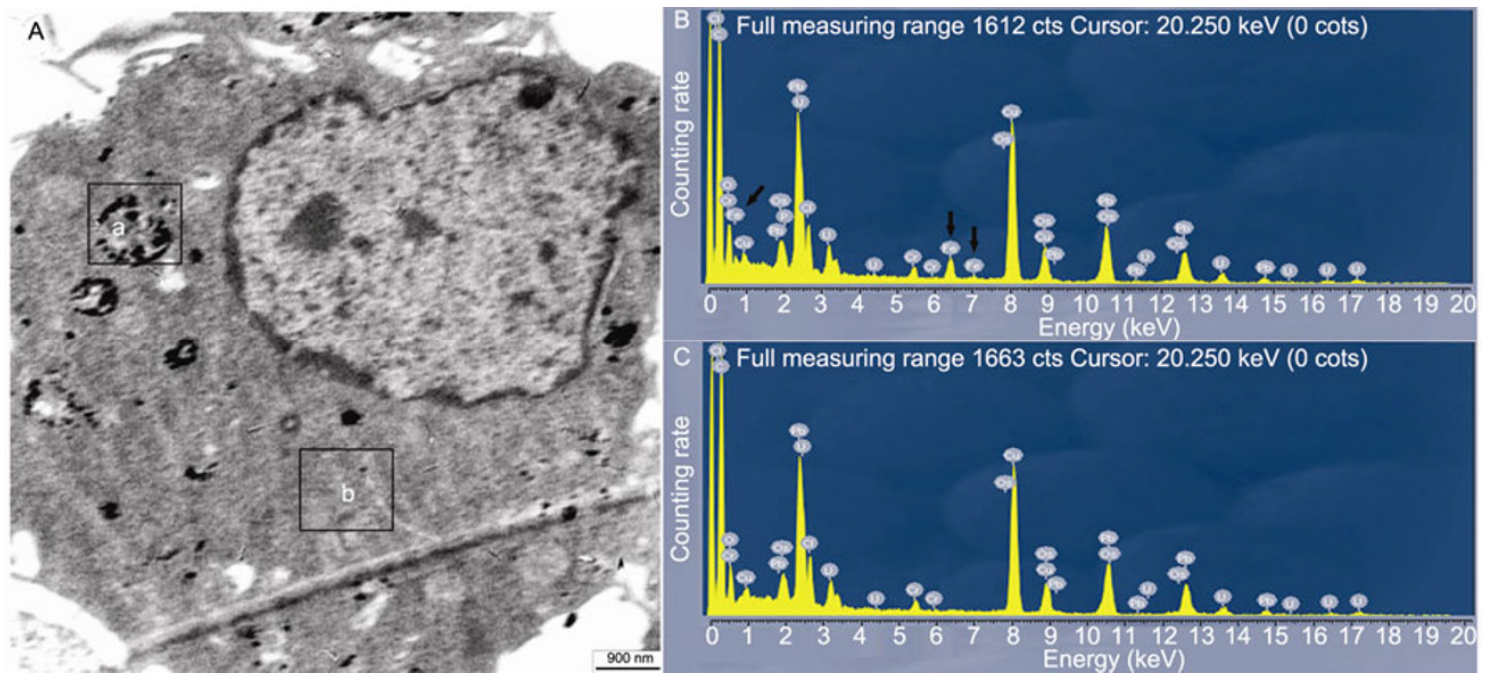

Figure 2 TEM-EDS analysis of RAW24.7 cells after incubation with SPIONs for $24 \mathrm{~h}$. A, The TEM image of a RAW24.7 cell; the framed areas a and b indicate the parts selected for EDS analyses. B and C, EDS spectrum showing the element composition of the selected areas above (a) and below (b). The arrows indicate iron composition of the membrane-bound vesicle. Note that the iron element was detected in area (a) which had membrane-bound particles, and not in area (b) which had no particles. 

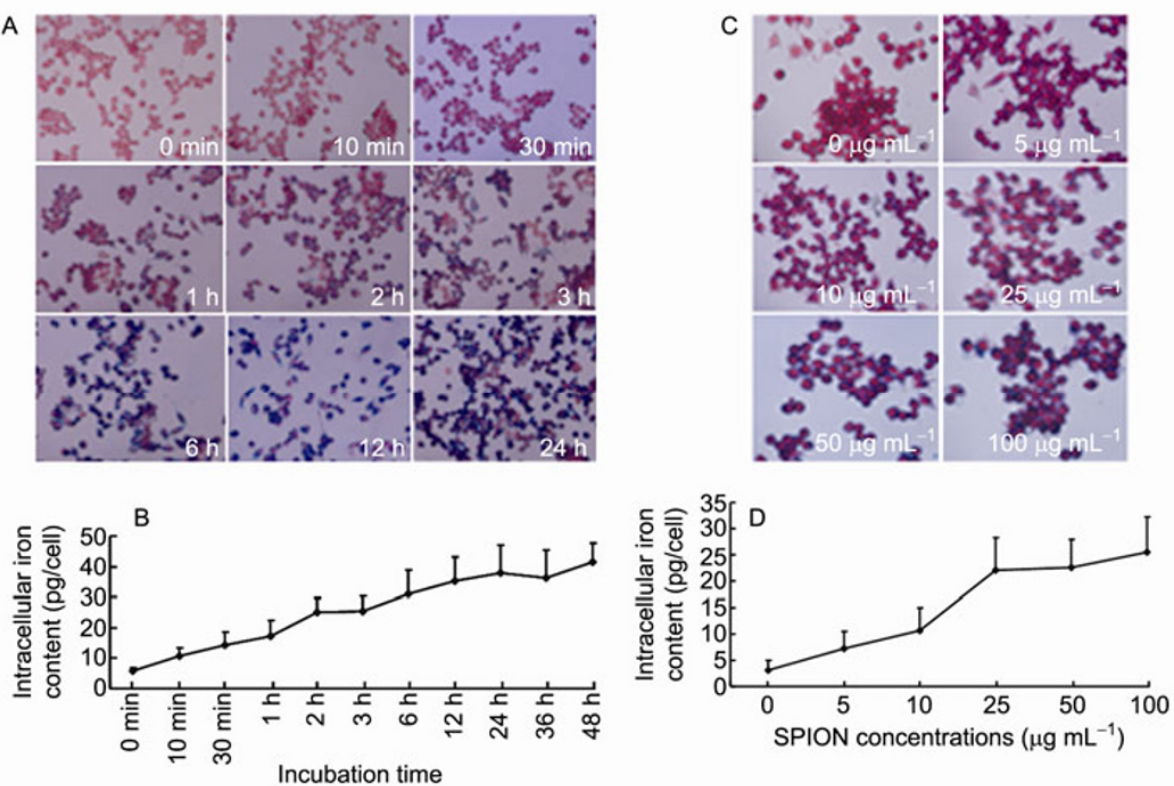

Figure 3 Kinetic characteristics of the internalization of SPIONs by RAW264.7 cells. A, Prussian blue staining showing the time-dependent manner of SPION internalization in RAW264.7 cells. Intracellular SPIONs are blue and the nuclei are red. Note that increased cellular uptake of SPIONs was observed with longer incubation times. B, Spectrometry analysis of SPION internalization at various times. C, Prussian blue staining showing the concentration-dependent manner of SPION internalization in RAW264.7 cells. D, Spectrophotometry assay of the internalization of SPIONs at various concentrations.

concentrations after a $3 \mathrm{~h}$ incubation; at $5 \mu \mathrm{gL}^{-1}$ the iron content was $(7.3 \pm 3.1) \mathrm{pg}$ iron/cell and at $25 \mu \mathrm{g} \mathrm{mL}^{-1}$ it was $(22.0 \pm 6.2) \mathrm{pg}$ iron/cell. No significant internalization occurred at concentrations above $25 \mu \mathrm{g}(\mathrm{Fe}) \mathrm{mL}^{-1}$; at $50 \mu \mathrm{g}$ $\mathrm{mL}^{-1}$ the iron content was about $(25.5 \pm 6.7) \mathrm{pg}$ iron/cell. These data indicate that the uptake of SPIONs by RAW264.7 cells may reach a saturated status after certain incubation time and at higher concentrations.

The TEM images further confirmed the time-dependent vesicle-bound manner of SPION internalization (Figure 4). In addition, after short incubation times, for example, 30 min or $1 \mathrm{~h}$ (Figure $4 \mathrm{C}$ and D), the SPIONs were mainly located in the secondary lysosomes which still contained homogeneous content with high electron density. However, after longer incubation of, say, 3 or $24 \mathrm{~h}$ (Figure 4E and F), the SPIONs appeared to be bound to the lumina membrane of $>500 \mathrm{~nm}$ organelles similar to multivesicular bodies that are located in the peripheral cytoplasm regions and away from the nucleus.

\subsection{The energy-dependent manner of SPION internal- ization in RAW264.7 cells}

To further analyze whether an endocytic process was involved in the internalization of SPIONs, we incubated RAW264.7 cells with SPIONs either at $4^{\circ} \mathrm{C}$ or in the presence of metabolic inhibitors. The TEM images showed that the internalization was clear if RAW264.7 cells were incubated with SPIONs alone at $37^{\circ} \mathrm{C}$ (Figure $5 \mathrm{~A}$ ). However, the internalization was extraordinarily hindered at $4^{\circ} \mathrm{C}$ (Figure 5B); SPIONs were seldom found inside the cell but

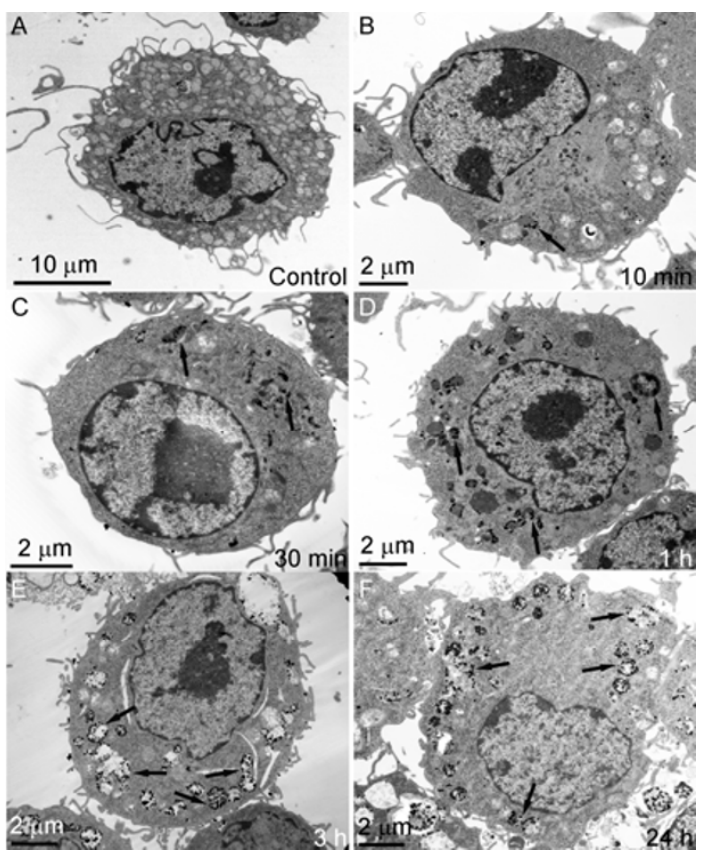

Figure 4 Representative TEM images of RAW264.7 cells after incubation with SPIONs for different time periods. A, Control cells without SPION incubation did not contain nanoparticles. B, Cells incubated with SPIONs for $10 \mathrm{~min}$. C, Cells incubated with SPION for $30 \mathrm{~min}$. D, Cells incubated with SPIONs for $1 \mathrm{~h}$. E, Cells incubated with SPIONs for $3 \mathrm{~h}$. F, Cells incubated with SPIONs for $24 \mathrm{~h}$. The arrows in A and B indicate the small nanoparticles seen after the short incubation times; the arrows in E and $\mathrm{F}$ indicate the large membrane-bound vesicular structures seen after the longer incubation times.

were primarily located in the extracellular environment close to the cell membrane. Co-incubation with metabolic 


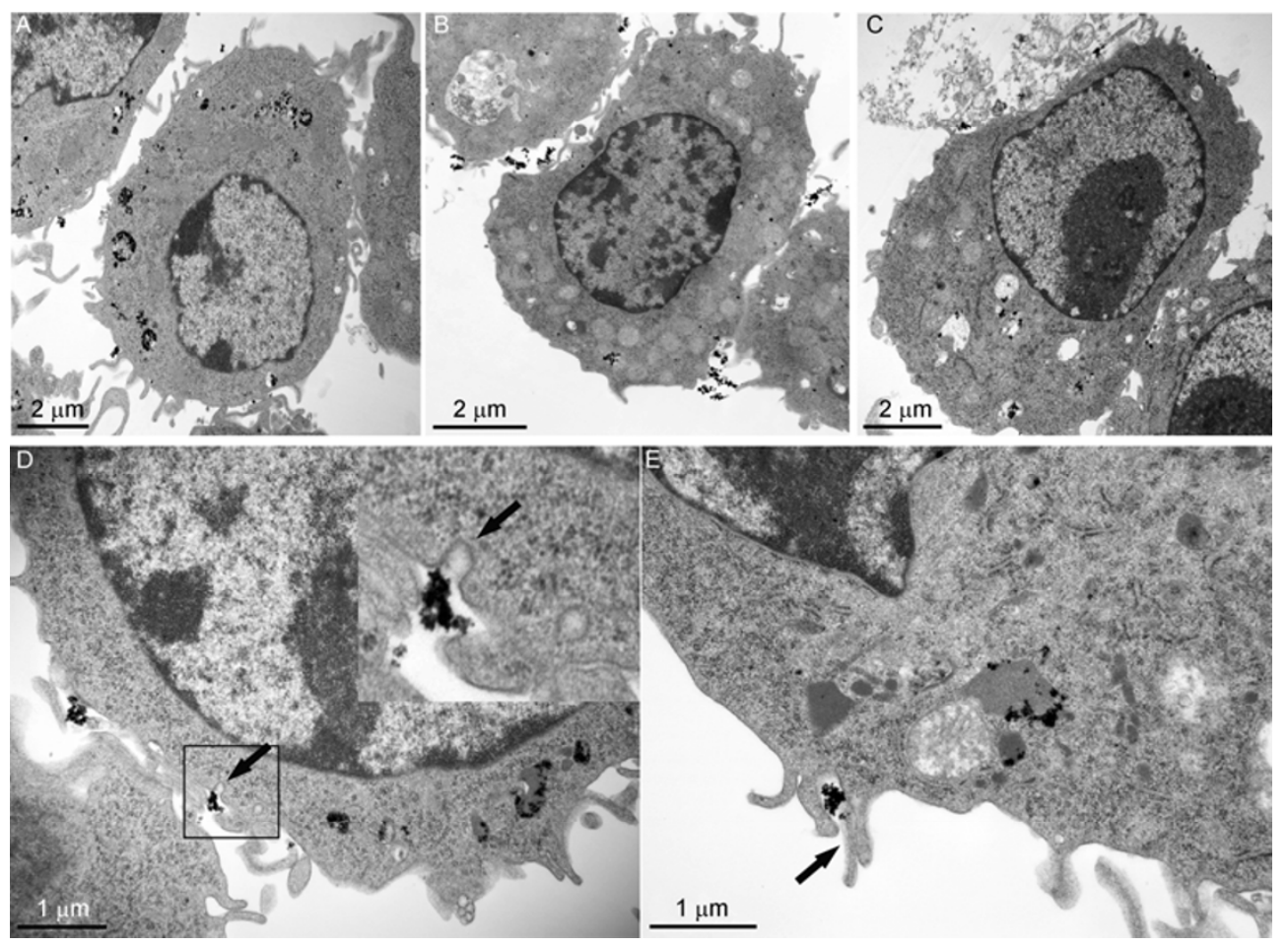

Figure 5 TEM images showing the evidence of endocytosis of SPIONs in RAW264.7 cells. A, Control (incubation with SPIONs at $37^{\circ} \mathrm{C}$ ). B, At $4^{\circ} \mathrm{C}$, cell uptake of SPIONs could hardly be observed, SPIONs were mostly observed in the extracellular environment close to the cytomembrane. C, Pretreatment with metabolic inhibitors (10 $\mathrm{mmol} \mathrm{L}^{-1} \mathrm{NaN}_{3}$ plus $50 \mathrm{mmol} \mathrm{L}^{-1}$ 2-deoxy-D-glucose) abolished the cellular uptake of SPIONs, very few iron oxide nanoparticles were found within the cytoplasm. D and E, Early intermediates in the process of internalization of SPIONs in RAW264.7 cells. In D, the arrows indicate $100 \mathrm{~nm}$ invaginations; in $\mathrm{E}$, the arrow indicates a protrusion (arrow) of the plasma membrane.

inhibitors $\left(10 \mathrm{mmol} \mathrm{L}^{-1}\right.$ sodium azide plus $50 \mathrm{mmol} \mathrm{L}^{-1}$ 2-deoxy-D-glucose) also abolished SPION internalization (Figure 5C).

Furthermore, Figure 5D showed an invagination of plasma membrane of approximately $100 \mathrm{~nm}$, suggesting that a clathrin-mediated endocytosis mechanism may be operating. Figure 5E indicated a protrusion of cellular membrane to the external milieu suggesting that macropinocytosis or phagocytosis may be involved in the uptake of SPIONs in RAW264.7 cells. Together, these results indicated that endocytosis was involved in the cellular internalization of SPIONs in RAW264.7 cells.

\subsection{Effects of various endocytic inhibitors on the in- ternalization of SPIONs}

To assess the role of each of the endocytic pathways in the internalization of SPIONs, the effects of various endocytic inhibitors were analyzed. Pretreatment of RAW264.7 cells with chlorpromazine (an inhibitor of clathrin-dependent endocytosis) drastically reduced the uptake of SPIONs (Figure 6B) compared with the uptake in the absence of any of the inhibitors (Figure 6A). The drugs filipin III and $\mathrm{M}-\beta-\mathrm{CD}$ that disturb the caveolin-dependent endocytosis both significantly suppressed the uptake of SPIONs by RAW264.7 cells (Figure 6C and D) with similar efficacies.
Co-incubation of RAW264.7 cells with chlorpromazine and filipin III further suppressed the uptake of SPIONs (Figure 6E). Pretreatment of RAW264.7 cells with amiloride (macropinocytosis inhibitor) clearly inhibited SPION internalization (Figure 6F). Pretreatment of RAW264.7 cells with the scavenger receptor ligand ox-LDL competitively antagonized the internalization of SPIONs (Figure 6G) compared with the control (Figure 6A). Pretreatment of RAW264.7 cells with cytochalasin D to inhibit actin polymerization significantly reduced the uptake level of the SPIONs (Figure 6H).

\subsection{Metabolic pathways of the internalized SPION in RAW264.7 cells}

The TEM images of the SPION-labeled RAW264.7 cells (Figure 7) showed that the intracellular SPIONs could be distributed into the daughter cells during mitosis. As shown in the TEM images (Figure 8A), fewer and fewer iron oxide nanoparticles were observed in the cytoplasm at prolonged incubation times; this was especially clear after incubation for $24 \mathrm{~h}$. No SPIONs were observed in other organelles such as the mitochondria, endoplasmic reticulum, or the nucleus. Similarly, Figure 8B illustrated that the blue pigments (representing SPION) were fewer in the daughter cells after $24 \mathrm{~h}$ or longer incubation time. The spectropho- 


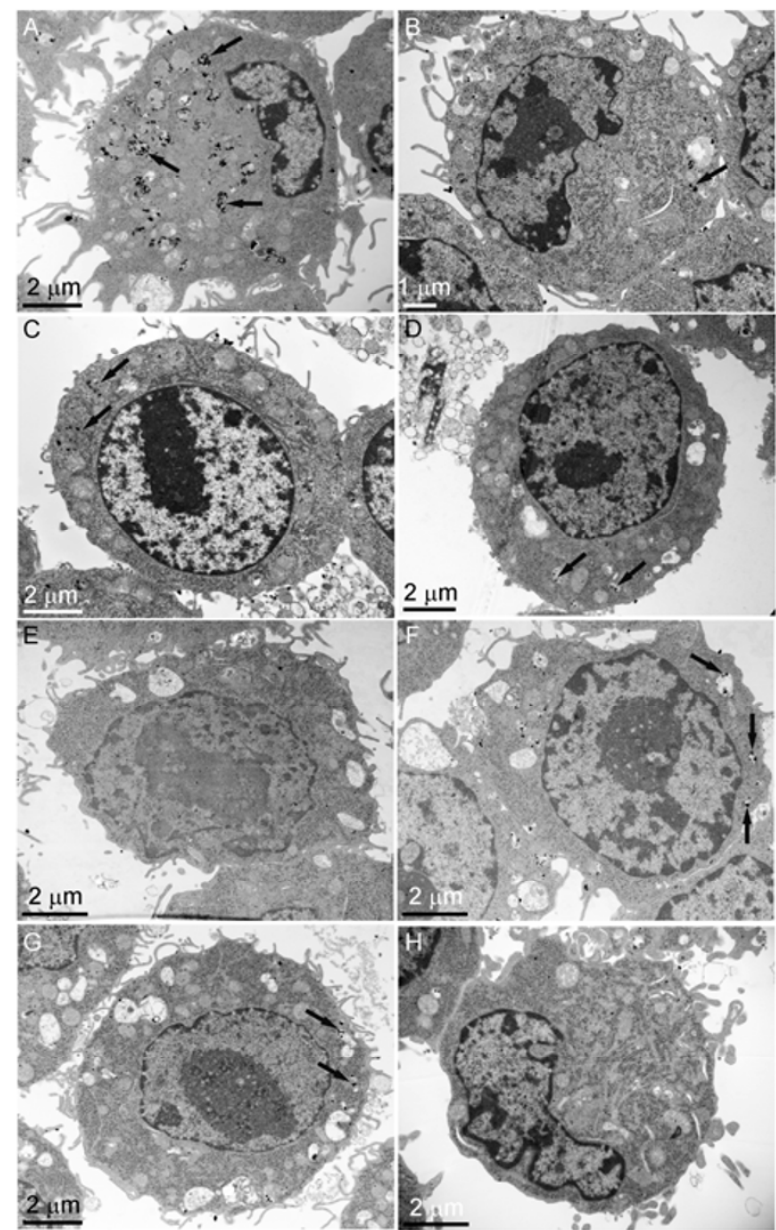

Figure 6 Representative TEM images showing the effects of various endocytic inhibitors on the internalization of SPIONs in RAW264.7 cells. Cells were pretreated with each of the inhibitors for $30 \mathrm{~min}$ followed by co-incubation with SPIONs for $1 \mathrm{~h}$. A, Control (SPIONs alone). B, SPIONs treated with chlorpromazine. C, SPIONs treated with Filipin III. D, SPIONs treated with methyl- $\beta$-cyclic dextrin. E, SPIONs treated with chlorpromazine plus filipin III. F, SPIONs treated with amiloride. G, SPIONs treated with ox-LDL. H, SPIONs treated with cytochalasin D. The internalization of the SPIONs was inhibited by all these endocytic inhibitors with similar efficacies. tometry of intracellular iron levels (Figure 8C) further confirmed that the cellular iron content decreased sharply after long incubation times, mainly because of the proliferation of RAW264.7 cells. The intracellular iron content reduced dramatically from $(39.2 \pm 9.7) \mathrm{pg}$ iron/cell (assayed immediately after a 6 -h pre-incubation) to $(3.4 \pm 1.2) \mathrm{pg}$ iron/cell after continuous incubation for $96 \mathrm{~h}$.

To further determine the fate of the intracellular SPIONs, the iron content in the culture medium of SPION-labeled RAW264.7 cells was also measured by ICP-MS. The results (Figure 8D) showed that the iron element could be detected in the culture medium and that the level of the extracellular iron element reached a peak at $1 \mathrm{~h}$, then gradually decreased. This observation indicated that the intracellular SPIONs released the iron into extracellular space by RAW264.7 cells either in the form of ferritin, or as free iron ion from the degradation of SPIONs or even as the iron oxide nanoparticle itself, possibly via exocytosis.

\subsection{Effect of SPION on the viability of RAW264.7 cells}

To assess the biocompatibility and biosafety of the intracellular iron oxide nanoparticles, the viability of the SPIONlabeled or unlabeled RAW264.7 cells was measured by MTT assay. The results (Figure 9) demonstrated that the viability of RAW264.7 cells was hardly affected by incubation with SPIONs at concentrations ranging from 5 to $50 \mu \mathrm{g} \mathrm{mL}$ for $12-48 \mathrm{~h}$. The cell viability was even inversely a little enhanced. Compared with the control for which the viability was set to $100 \%$, after a $48 \mathrm{~h}$ SPION incubation, the viability of RAW264.7 cell was $121.6 \% \pm 22.5 \%, 122.3 \% \pm 20.5 \%$, $105.6 \% \pm 33.9 \%$ and $95.1 \% \pm 27.3 \%$ at an iron concentration of $5,10,25$ and $50 \mu \mathrm{g} \mathrm{mL}{ }^{-1}$, respectively. At a fixed iron concentration of $50 \mu \mathrm{g} \mathrm{mL}$, the viability was $106.5 \% \pm$ $32.7 \%, 111.6 \% \pm 37.8 \%$ and $110.3 \% \pm 37.0 \%$ after incubation for 12,24 and $36 \mathrm{~h}$, respectively. No significant difference in cell viability was observed among the differently treated cells. The internalized SPIONs also did not significantly

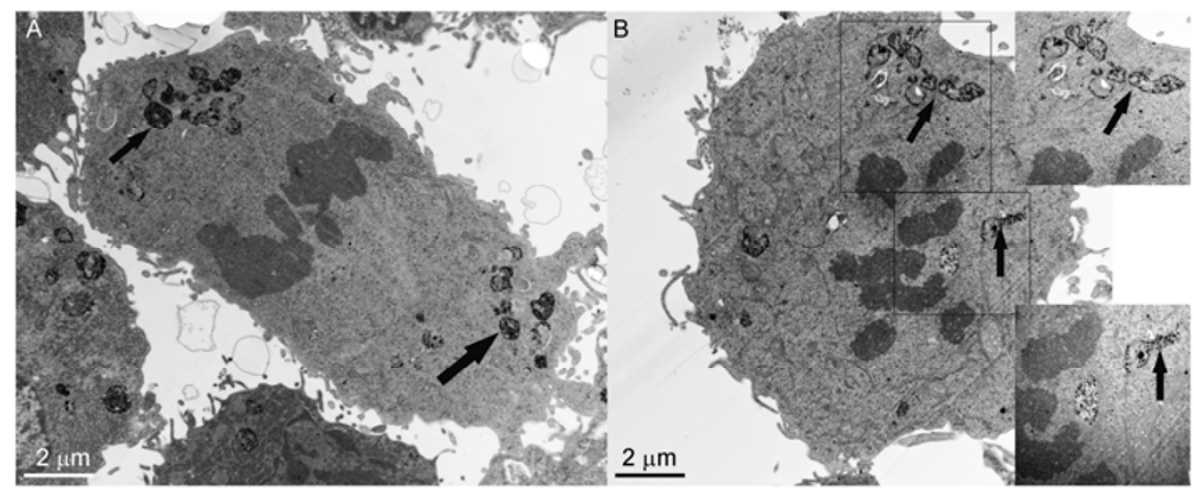

Figure 7 TEM images showing the morphology of mitosis of the SPION-labeled RAW264.7 cells. A, During the process of mitosis, vesicle-coated SPIONs are located at the two poles of the dividing cell (arrows). B, As a result of breakdown of nuclear membrane during mitosis, some vesicle-coated SPIONs (arrows) approach the chromosomes. 

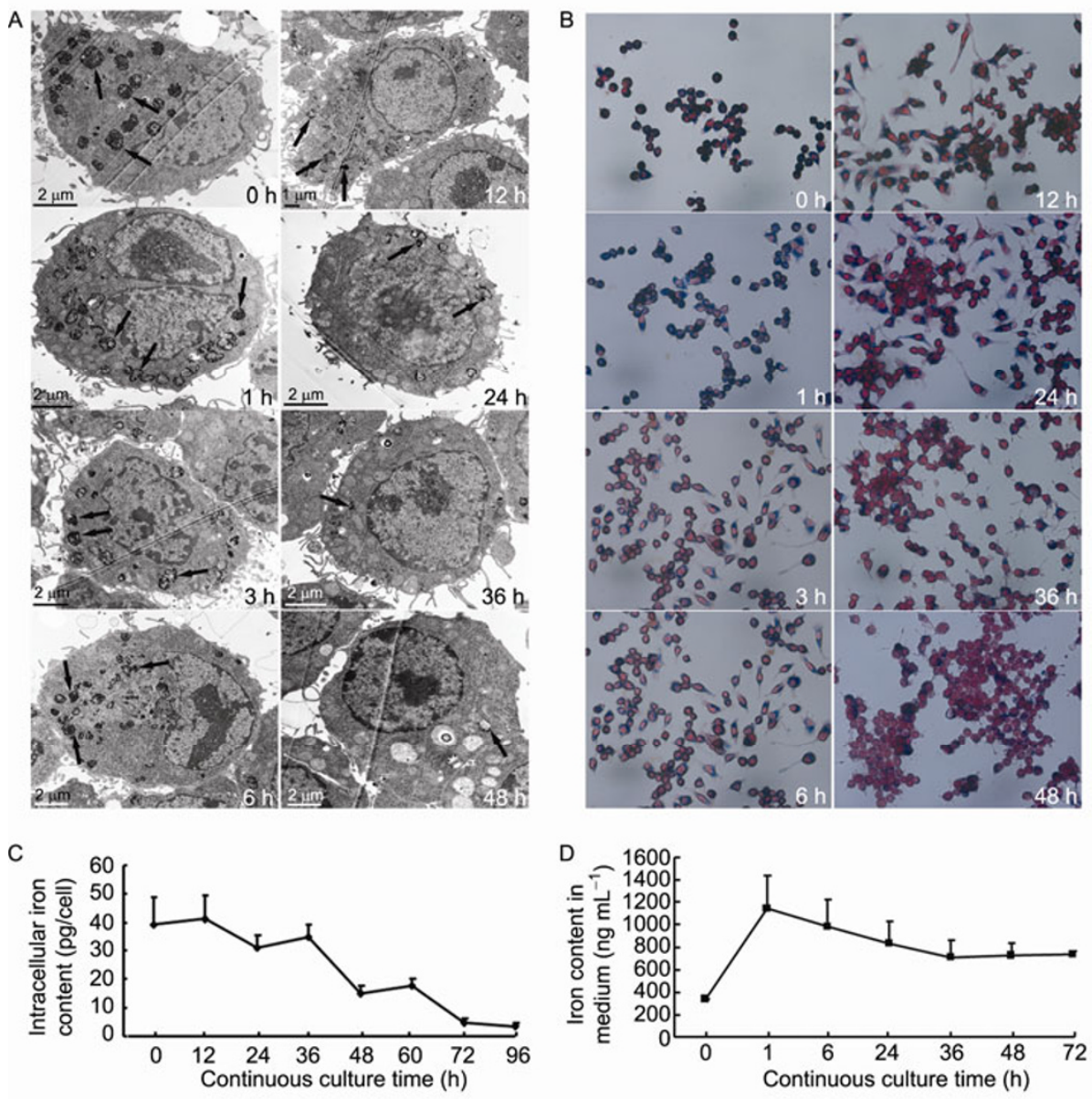

Figure 8 Metabolic pathways of the internalized SPIONs in RAW264.7 cells. A, TEM images of SPION-labeled RAW 264.7 cells at different continuous culture times after pre-incubation with SPIONs for $6 \mathrm{~h}$. Vesicle-bound SPIONs (arrows) in the cytoplasm were fewer at longer incubation times. B, Prussian blue staining of SPION-labeled RAW 264.7 cells at different continuous culture times after pre-incubation with SPIONs for 6 h. Fewer blue pigments were observed in the cytoplasm after longer incubation times. C, Spectrophotometry of RAW 264.7 cells at different continuous culture times after pre-incubation with SPIONs for $6 \mathrm{~h}$. Iron content decreased gradually with longer incubation times. D, Inductively coupled plasma mass spectroscopy showing the iron content in the continuous culture medium at various times. The result indicates that iron can be released into the culture medium by the SPION-labeled RAW 264.7 cells.

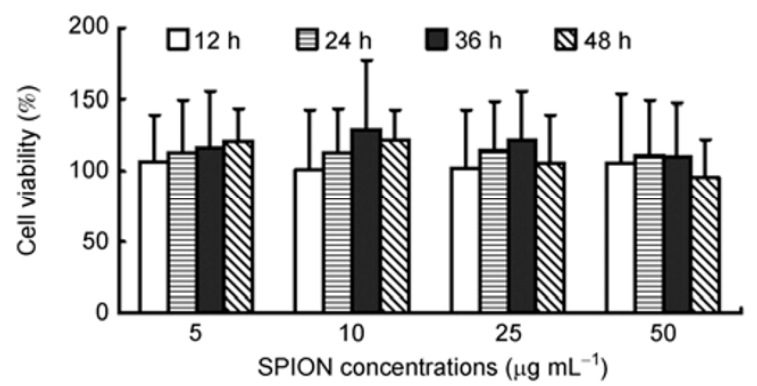

Figure 9 MTT assay showing the effect of SPIONs on the viability of RAW264.7 cells. Compared with the control (without SPION incubation) for which the cellular viability was set to $100 \%$, (not shown), no marked decrease in cell viability was found at the different incubation times $(12,24$, 36 and $48 \mathrm{~h}$ ) for the indicated SPION concentrations.

affect the proliferation of RAW264.7cells, as indicated by the levels of mitosis (Figure 7) and cell viability (Figure 9).

\subsection{Effects of SPIONs on ROS generation and mito- chondrial membrane potential in RAW264.7 cells}

To further evaluate the potential cytotoxicity of SPIONs, flow cytometry was performed to detect the intracellular ROS production and mitochondrial membrane potential $\left(\Delta \Psi_{\mathrm{m}}\right)$ of SPION-labeled RAW264.7 cells. The intracellular ROS production was estimated by the fluorescent intensity of $2^{\prime}, 7^{\prime}$-dichlorofluorescein, a rightward shift of the fluorescence trace indicates an increase in production and vice versa. The results showed that there were no apparent shifts in the fluorescence traces and no significant differences in the values of the DCF fluorescent intensity after the cells were labeled by SPION at various incubation times (Figure $10 \mathrm{~A}$ and $\mathrm{B}$ ). A decrease in mitochondrial membrane potential is usually indicative of cell apoptosis. Our results demonstrated that the internalized SPIONs in RAW264.7 cells had no significant effect on mitochondrial membrane potential (Figure 10C and D). This result combined with the 

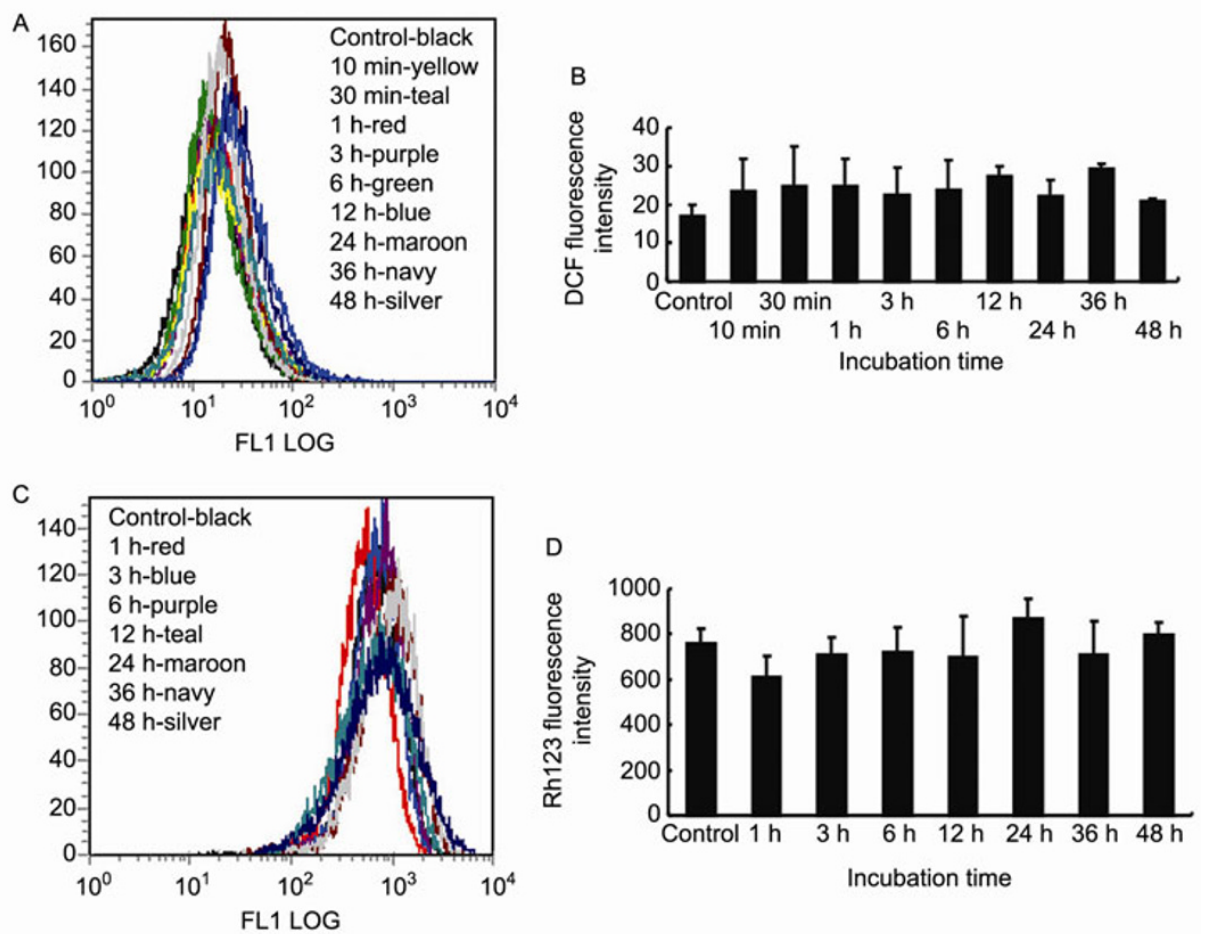

Figure 10 Flow cytometry showing the effects of SPIONs on ROS production and the mitochondrial membrane potential $\left(\Delta \Psi_{\mathrm{m}}\right)$ in RAW264.7 cells. A and C, Representative traces of DCF and Rh123 fluorescence intensities, respectively, without and with SPION incubation. Note, compared with the control (without SPION), the DCF and Rh123 traces showed no significant shift after incubation with SPIONs. B and D, Corresponding statistical bar graphs. $P>0.05$ for each individual incubation time versus the control.

cell viability data (Figure 9) and the mitosis data (Figure 7), clearly showed that the SPIONs had no obvious toxicity to RAW264.7 cells, suggesting their potentially high biocompatibility.

\subsection{Effect of SPIONs on the intracellular iron metabo- lism of RAW264.7 cells}

To detect changes in the main proteins of intracellular iron metabolism at the mRNA and protein levels after the uptake and metabolism of SPIONs in RAW264.7 cells, real time RT-PCR and Western blot analyses were carried out. As shown in Figure 11, the internalized SPIONs had no effect on iron regulatory protein 2 (IRP2) at either the mRNA or protein levels in RAW264.7 cells. The ferritin light chain (ferritin-L) that is responsible for iron storage was sharply upregulated at the mRNA level in RAW264.7 cells, and a consistent upregulation at the protein level in a time- and dose-dependent manner was also seen. Ferroportin 1 that functions as an iron exporter displayed no significant change at the protein level but was obviously upregulated the mRNA level in RAW264.7 cells.

\section{Discussion}

In the present study, we report the successful development of dimercaptosuccinic acid coated SPION with high biocompatibility. The leading mechanism of SPION internalization is endocytosis, an energy dependent process that can be blocked when incubations are performed at low temperature or in ATP depleted conditions. Our data did not suggest a mechanical penetration mechanism, but rather, that multiple endocytic signaling pathways are involved in the SPION internalization. The endocytic pathways include several subcategories as mentioned above, and it is believed that such a diverse range of mechanisms is selectively utilized by cells to accomplish different tasks.

Clathrin-dependent endocytosis is the most well-defined and characterized endocytic pathway. Internalization occurs when the clathrin coat on the plasma membrane forms invaginations in the membrane leading to the budding of clathrin-coated vesicles [23]. The clathrin-coated vesicles ranged in size from $\sim 100$ to $150 \mathrm{~nm}$ in diameter [24,25], in agreement with our results. Chlorpromazine is a cationic amphipathic drug which inhibits clathrin-dependent endocytosis by a mechanism that involves the loss of clathrin and the AP2 adaptor complex from the cell surface and their artificial assembly on endosomal membranes [26]. Pretreatment of RAW264.7 cells with chlorpromazine drastically reduced their uptake of SPIONs, suggesting that a clathrin-dependent pathway was involved in the uptake of SPIONs by RAW264.7 cells. However, chlorpromazine has been shown to block phagocytosis in immune cells such as 


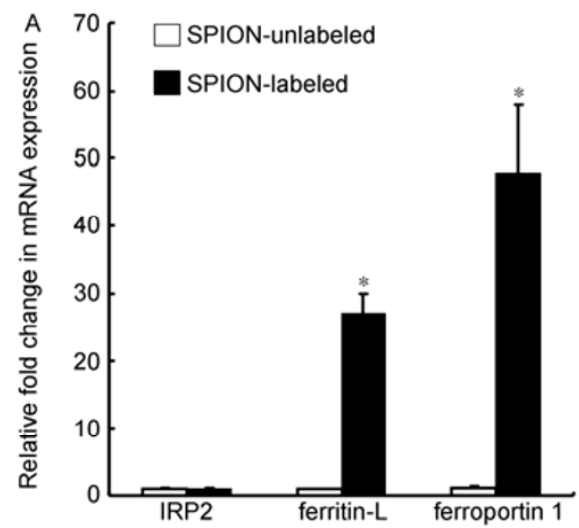

B

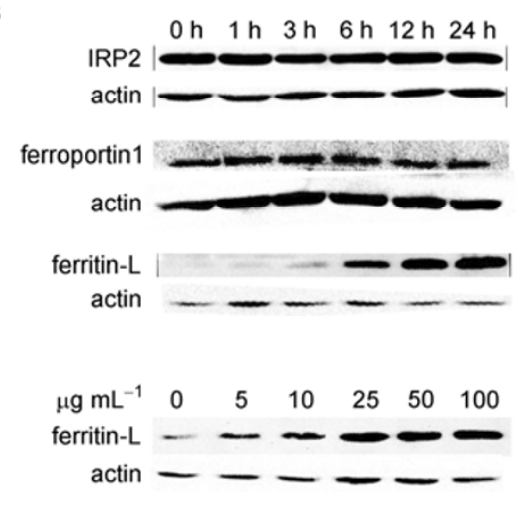

Figure 11 The mRNA and protein expression levels of iron metabolism-related proteins in the SPION-(un)labeled RAW264.7 cells. A, Real-time RT-PCR. Note that the transcription levels of ferritin-L and ferroportin 1 were significantly up-regulated by SPIONs $(*, P<0.05$ versus SPION-unlabeled cells), but no change of IRP2 expression was observed. B, Western blot analysis. The protein level of ferritin-L was significantly up-regulated by SPIONs both in a timeand a concentration-dependent manner. The protein levels of IRP2 and ferroportin 1 were not affected by SPIONs.

neutrophils and macrophages $[27,28]$. Therefore, in addition to affecting clathrin-coated pits, chlorpromazine may also perturb phagocytosis and macropinocytosis.

Caveolae are cholesterol- and sphingolipid-rich subdomains of plasma membranes or lipid rafts [29]. Caveolin is the major protein in the composition of caveolae. Drugs that sequester (filipin III) or deplete (MBCD) membrane cholesterol have been used as indicators of the requirement for caveolae or rafts in the endocytic mechanism [30,31]. Our data suggest that the internalization pathways for SPIONs in RAW264.7 cells are both caveolae- and lipid raft-dependent. $\mathrm{M} \beta \mathrm{CD}$ can also reorganize the actin cytoskeleton which plays a potential role in the sequence of events that are integral to the endocytic machinery $[32,33]$. We found that $\mathrm{M} \beta \mathrm{CD}$ treatment inhibited dramatically the internalization of iron oxide nanoparticles in agreement with the earlier study.

Our data suggests that clathrin- and caveolin-independent endocytosis is not involved in SPION internalization in RAW264.7 cells, because the uptake was almost totally abolished by inhibitors of clathrin-dependent and caveolin-dependent pathways.

Some reports have shown that the internalization of nanoparticles into mammalian cells could occur via macropinocytosis or phagocytosis [34,35]. In the better characterized micropinocytosis machinery, it was reported that this process usually proceed with the formation of actin-associated membrane protrusions rather than with membrane invagination [36]. Macropinocytosis can be inhibited by amiloride and its analogs by blocking the activity of the $\mathrm{Na}^{+} / \mathrm{H}^{+}$exchanger in the plasma membrane [37]. Our results indicated morphologically and pharmacologically that macropinocytosis was also involved in the cellular uptake of SPIONs. The iron oxide nanoparticles used in the present study could adsorb proteins from the culture medium supplemented with heat-inactivated FBS during incubation and some were suspended as aggregates but not as single particles. It is, therefore, possible that the nanoparticles were phagocytosed through nonspecific scavenger receptors and the competitive experiment using the scavenger receptor ligand ox-LDL suggested that scavenger receptors were involved in the internalization of SPIONs in RAW264.7 cells. Recent studies have indicated that, in addition to its involvement in the formation of macropinosomes and phagosomes, the actin cytoskeleton takes part in the regulation of different endocytic pathways [38,39]. Our data indicated that actin was recruited for the internalization of SPIONs and was involved in the initiation of endocytosis.

Once internalized, fusion with lysosomes is considered to be the terminal degradative pathway for many endocytosed macromolecules which follow the sequential passage through early and late endosomes [40]. A lysosome-degradating pathway has been commonly thought to be the metabolic pathway for SPIONs. Both the low $\mathrm{pH}$ environment of endosomes/lysosomes and some intracellular Fe-chelating substances (i.e., phosphate, nucleotides and dicarboxylic acids, etc.) are responsible for the solubilization of those iron oxide particles [41,42]. Here, three possible mechanisms for the metabolic fate of the internalized SPIONs in RAW264.7 cells are proposed. First, the internalized SPIONs are distributed to daughter cells as a result of cell division; second, the internalized SPIONs are degraded in the low $\mathrm{pH}$ environment of lysosome and free iron could be released into the intracellular iron metabolic pool; third, although no direct evidence of exocytosis was provided in this study, the intact iron oxide nanoparticles may potentially be exocytosed out of RAW264.7 cells. The first possibility is evidenced by the present data and is considered by us to be the main route from the viewpoint of the physiological degradation rate of lysosome and the homeostasis of intracellular environment. The second possibility is supported by our data that iron metabolism related proteins are affected. As a third potential metabolic pathway for nanomaterials, exocytosis has been evidenced in a study by Jin et al. [43] and is also suggested by the present data that detected extracellular iron. 
Our study also showed that intracellular SPIONs do not have a significant effect on cell viability, ROS production and mitochondrial membrane potential, suggesting good biocompatibility of the SPIONs used in this study. Conversely, our MTT results indicated that SPIONs could slightly promote RAW264.7 cell growth. Similarly, a study by Wang et al. [40] suggested that intracellular SPIONs can promote cell growth of hMSCs by diminishing intracellular $\mathrm{H}_{2} \mathrm{O}_{2}$ and accelerating the cell cycle progress by affecting the cell cycle control molecules. Therefore, the results helped exclude the possibility that the iron detected in the continuous culture medium was released by dead ruptured cells. Rather, our data suggested the exocytosis of SPIONs by RAW 264.7 cells.

SPIONs are generally composed of a core of iron oxide nanoparticles and various modifying coatings. The idea that the internalized iron oxide nanoparticles can be degraded to release free iron into the labile iron pool has been commonly accepted $[44,45]$. Iron is one of the pivotal nutrients for almost all organisms but, by stimulating ROS production, it is toxic when present in excess. Cellular iron levels are tightly regulated to remain within the physiologically optimal range, satisfying the metabolic needs but preventing the toxicity of iron overload. Among the main proteins involved in cell iron metabolism, the iron regulatory proteins (IRPs) are considered as the central regulators of intracellular iron homeostasis. IRPs bind to the iron responsive elements (IREs) in the untranslated regions of the transcripts of proteins that function in the uptake, storage, and usage of iron in a cell to regulate the expressions of these proteins [46]. We hypothesized that the release of iron from the degraded SPIONs into the cytoplasm may disturb the intracellular labile iron pool and induce IRP2 degradation leading to the upregulation of ferritin-L. However, our data showed the opposite result for the IRP2 response to SPIONs at the mRNA and protein levels. That IRP2 showed no response to SPIONs in RAW264.7 cells can be explained by the following considerations: synthesis of ferritin- $\mathrm{L}$ is directly coupled to iron status; preexisting and upregulated ferritin-L mRNA allowed the cells to rapidly increase the expression of ferritin-L [47]; this response led to rapid chelation of the increased intracellular iron induced by the degradation of SPION and IRP2 degradation was avoided. Several studies have recently reported that high intracellular iron could directly upregulate ferroportin gene transcription [48,49], leading to substantial increases in ferroportin mRNA, as shown in this present study. Our results showed that, after SPION exposure, ferroportin 1 was high at the mRNA level but not at the protein level. Possible explanations for this phenomenon would be complicated and might include regulatory differences between transcription and translation, post-transcriptional modifications, and even the circadian oscillation of ferroportin. Nonetheless, this observation still needs further investigation to unveil the potential mechanisms underlying the marginal affect on the protein level.
Three kinds of metabolic direction for the intracellular free iron to go in have been considered: (i) Free iron exerts its physiological function in many metabolic processes; (ii) it is stored in ferritin; or (iii) it is exported out of the cell [50]. Some studies have reported that iron-laden macrophage can excrete ferritin out of the cytoplasm [51,52]. In the present study, the ICP-MS results suggested that SPION-preloaded RAW264.7 cells can export iron into the extracellular environment, possibly by ferroportin 1 or in the form of ferritin, and by exocytosis even as SPIONs.

In summary, in the present study the potential uptake mechanisms, the metabolic process and the biological effects of intracellular SPION on RAW264.7 cells were investigated. The results suggested that no single mechanism was solely or predominantly responsible for the cellular uptake of nanoparticles in a giving cell line. Instead, differential pathways or combinations of these pathways may function cooperatively for the cellular uptake of nanoparticles. The results also suggested that both the pharmacokinetics and the metabolic effect should be taken into consideration when SPIONs are administered in vivo either as an imaging contrast medium or a therapeutic tool. In addition, our study raised important questions like: Why does a cell employ so many machineries for the uptake of a nanoparticle? Does this phenomenon presage a new biological law that cells mobilize all their capabilities to cater for an "alien" such as a nanoparticle? What are the relationships among different endocytic pathways? Some of the answers to these questions may emerge in future work.

This work was supported by the National Basic Research Program of China, Ministry of Science and Technology of China (Grant Nos. $2006 C B 933202$ and 2011CB933504) and in part by the National High Technology Research and Development Program of China (Grant No. 2008AA02Z425) and a grant from the National Natural Science Foundation of China (Grant No. 81071072). We thank Drs. Xiong Fei and Zhang Yu for nanomaterial preparation and Dr. Soong Tuck Wah for language editing of the manuscript.

1 Zhang K H, Guo L L, Cai Z, et al. Labeling efficiency and cell viability of human amniotic mesenchymal cells labeled with silica coated-superparamagnetic iron oxide nanoparticles. Sci Sin Vitae, 2010, 40: 1154-1160

2 Neri M, Maderna C, Cavazzin C, et al. Efficient in vitro labeling of human neural precursor cells with superparamagnetic iron oxide particles: relevance for in vivo cell tracking. Stem Cells, 2008, 26: 505-516

3 Veiseh O, Gunn J W, Kievit F M, et al. Inhibition of tumor-cell invasion with chlorotoxin-bound superparamagnetic nanoparticles. Small, 2009, 5: 256-264

4 Johannsen M, Gneveckow U, Thiesen B, et al. Thermotherapy of prostate cancer using magnetic nanoparticles: feasibility, imaging, and three-dimensional temperature distribution. Eur Urol, 2007, 52: 16531661

5 Jing X H, Yang L, Duan X J, et al. In vivo MR imaging tracking of magnetic iron oxide nanoparticle labeled, engineered, autologous bone marrow mesenchymal stem cells following intra-articular injection. Joint Bone Spine, 2008, 75: 432-438

6 Neuwelt E A, Hamilton B E, Varallyay C G, et al. Ultrasmall superparamagnetic iron oxides (USPIOs): a future alternative magnetic resonance (MR) contrast agent for patients at risk for nephrogenic 
systemic fibrosis (NSF)? Kidney Int, 2009, 75: 465-474

7 Huth S, Lausier J, Gersting S W, et al. Insights into the mechanism of magnetofection using PEI-based magnetofectins for gene transfer. J Gene Med, 2004, 6: 923-936

8 Mayor S, Pagano R E. Pathways of clathrin-independent endocytosis. Nat Rev Mol Cell Biol, 2007, 8: 603-612

9 Taylor P R, Martinez-Pomares L, Stacey M, et al. Macrophage receptors and immune recognition. Annu Rev Immunol, 2005, 23: 901-944

10 Lopez C F, Nielsen S O, Moore P B, et al. Understanding nature's design for a nanosyringe. Proc Natl Acad Sci USA, 2004, 101: 4431-4434

11 Kostarelos K, Lacerda L, Pastorin G, et al. Cellular uptake of functionalized carbon nanotubes is independent of functional group and cell type. Nat Nanotechnol, 2007, 2: 108-113

12 Davda J, Labhasetwar V. Characterization of nanoparticle uptake by endothelial cells. Int J Pharm, 2002, 233: 51-59

13 Kam N W, Liu Z, Dai H. Carbon nanotubes as intracellular transporters for proteins and DNA: an investigation of the uptake mechanism and pathway. Angew Chem Int Ed Engl, 2006, 45: 577-581

14 Park J S, Han T H, Lee K Y, et al. N-acetyl histidine-conjugated glycol chitosan self-assembled nanoparticles for intracytoplasmic delivery of drugs: endocytosis, exocytosis and drug release. J Control Release, 2006, 115: 37-45

15 Arbab A S, Bashaw L A, Miller B R, et al. Characterization of biophysical and metabolic properties of cells labeled with superparamagnetic iron oxide nanoparticles and transfection agent for cellular MR imaging. Radiology, 2003, 229: 838-846

16 Pawelczyk E, Arbab A S, Pandit S, et al. Expression of transferrin receptor and ferritin following ferumoxides-protamine sulfate labeling of cells: implications for cellular magnetic resonance imaging. NMR Biomed, 2006, 19: 581-592

17 Corot C, Robert P, Idée J M, et al. Recent advances in iron oxide nanocrystal technology for medical imaging. Adv Drug Deliv Rev, 2006, 58: 1471-1504

18 Libby P. Inflammation in atherosclerosis. Nature, 2002, 420: 868-874

19 Boyle J J. Macrophage activation in atherosclerosis: pathogenesis and pharmacology of plaque rupture. Curr Vasc Pharmacol, 2005, 3: 63-68

20 Nardin A, Abastado J P. Macrophages and cancer. Front Biosci, 2008, 13: 3494-3505

21 Molday R S. Magnetic iron-dextran microspheres. US Patent, No. 4452773, 1984

22 Fauconnier N, Bee A, Roger J, et al. Synthesis of aqueous magnetic liquids by surface complexation of maghemite nanoparticles. J Mol Liq, 1999, 83: 233-242

23 Goldstein J L, Anderson R G, Brown M S. Coated pits, coated vesicles, and receptor-mediated endocytosis. Nature, 1979, 279: 679-685

24 Conner S D, Schmid S L. Regulated portals of entry into the cell. Nature, 2003, 422: 37-44

25 Takei K, Haucke V. Clathrin-mediated endocytosis: membrane factors pull the trigger. Trends Cell Biol, 2001, 11: 385-391

26 Wang L H, Rothberg K G, Anderson R G. Mis-assembly of clathrin lattices on endosomes reveals a regulatory switch for coated pit formation. J Cell Biol, 1993, 123: 1107-1117

27 Elferink J G. Chlorpromazine inhibits phagocytosis and exocytosis in rabbit polymorphonuclear leukocytes. Biochem Pharmacol, 1979, 28: 965-968

28 Watanabe S, Hirose M, Miyazaki A, et al. Calmodulin antagonists inhibit the phagocytic activity of cultured Kupffer cells. Lab Invest, 1988, 59: 214-218

29 Lajoie P, Nabi I R. Regulation of raft-dependent endocytosis. J Cell Mol Med, 2007, 11: 644-653

30 Kitajima Y, Sekiya T, Nozawa Y. Freeze-fracture ultrastructural alterations induced by filipin, pimaricin, nystatin and amphotericin B in the plasmia membranes of Epidermophyton, Saccharomyces and red complex-induced membrane lesions. Biochim Biophys Acta, 1976, 455: 452-465
31 Kilsdonk E P, Yancey P G, Stoudt G W. Cellular cholesterol efflux mediated by cyclodextrins. J Biol Chem, 1995, 270: 17250-17256

32 Kwik J, Boyle S, Fooksman D, et al. Membrane cholesterol, lateral mobility, and the phosphatidylinositol 4,5-bisphosphate-dependent organization of cell actin. Proc Natl Acad Sci USA, 2003, 100: 13964-13969

33 Qualmann B, Kessels M M, Kelly R B. Molecular links between endocytosis and the actin cytoskeleton. J Cell Biol, 2000, 150: F111-F116

34 Raynal I, Prigent P, Peyramaure S, et al. Macrophage endocytosis of superparamagnetic iron oxide nanoparticles: mechanisms and comparison of ferumoxides and ferumoxtran-10. Invest Radiol, 2004, 39: 56-63

35 Harush-Frenkel O, Debotton N, Benita S, et al. Targeting of nanoparticles to the clathrin-mediated endocytic pathway. Biochem Biophys Res Commun, 2007, 353: 26-32

36 Jones A T. Macropinocytosis: searching for an endocytic identity and role in the uptake of cell penetrating peptides. J Cell Mol Med, 2007, 11: 670-684

37 West M A, Bretscher M S, Watts C. Distinct endocytotic pathways in epidermal growth factor-stimulated human carcinoma A431 cells. J Cell Biol, 1989, 109: 2731-2739

38 Kaksonen M, Toret C P, Drubin D G. Harnessing actin dynamics for clathrin mediated endocytosis. Nat Rev Mol Cell Biol, 2006, 7: 404-414

39 Merrifield C J. Seeing is believing: imaging actin dynamics at single sites of endocytosis. Trends Cell Biol, 2004, 14: 352-358

40 Wang S W, Yang C S, Chen Y C. The promotion of human mesenchymal stem cell proliferation by superparamagnetic iron oxide nanoparticles. Biomaterials, 2009, 30: 3645-3651

41 Skotland T, Sontum P C, Oulie I. In vitro stability analyses as a model for metabolism of ferromagnetic particles (Clariscan), a contrast agent for magnetic resonance imaging. J Pharm Biomed Anal, 2002, 28 : 323-329

42 Arbab A S, Wilson L B, Ashari P, et al. A model of lysosomal metabolism of dextran coated superparamagnetic iron oxide (SPIO) nanoparticles: implications for cellular magnetic resonance imaging. NMR Biomed, 2005, 18: 383-389

43 Jin H, Heller D A, Strano M S. Single-particle tracking of endocytosis and exocytosis of single-walled carbon nanotubes in NIH-3T3 cells. Nano Lett, 2008, 8: 1577-1585

44 Pouliquen D, Le Jeune J J, Perdrisot R, et al. Iron oxide nanoparticles for use as an MRI contrast agent: pharmacokinetics and metabolism. Magn Reson Imaging, 1991, 9: 275-283

45 Okon E, Pouliquen D, Okon P, et al. Biodegradation of magnetite dextran nanoparticles in the rat. A histologic and biophysical study. Lab Invest, 1994, 71: 895-903

46 Hentze M W, Muckenthaler M U, Andrews N C. Balancing acts: molecular control of mammalian iron metabolism. Cell, 2004, 117: 285-297

47 Coulson R M, Cleveland D W. Ferritin synthesis is controlled by iron-dependent translational derepression and by changes in synthesis/transport of nuclear ferritin RNAs. Proc Natl Acad Sci USA, 1993, 90: 7613-7617

48 Liu X B, Hill P, Haile D J. Role of the ferroportin iron-responsive element in iron and nitric oxide dependent gene regulation. Blood Cells Mol Dis, 2002, 29: 315-326

49 Aydemir F, Jenkitkasemwong S, Gulec S, et al. Iron loading increases ferroportin heterogeneous nuclear RNA and mRNA levels in murine J774 macrophages. J Nutr, 2009, 139: 434-438

50 Eisenstein R S. Iron regulatory proteins and the molecular control of mammalian iron metabolism. Annu Rev Nutr, 2000, 20: 627-662

51 Yuan X M, Li W, Baird S K, et al. Secretion of ferritin by iron-laden macrophages and influence of lipoproteins. Free Radic Res, 2004, 38: 1133-1142

52 Leimberg M J, Prus E, Konijn A M, et al. Macrophages function as a ferritin iron source for cultured human erythroid precursors. J Cell Biochem, 2008, 103: 1211-1218

Open Access This article is distributed under the terms of the Creative Commons Attribution License which permits any use, distribution, and reproduction in any medium, provided the original author(s) and source are credited. 